\title{
The Italian Seismic Bulletin: strate- gies, revised pickings and locations of the central Italy seismic sequence
}

\author{
Marchetti A., M. G. Ciaccio, A. Nardi, A. Bono, F. M. Mele, L. Margheriti, A. Rossi, P. Battelli, \\ C. Melorio, B. Castello, V. lauciani, M. Berardi, C. Castellano, L. Arcoraci, G. Lozzi, A. \\ Battelli, C. Thermes, N. Pagliuca, G. Modica, A. Lisi, L. Pizzino, P. Baccheschi, S. Pintore, M. \\ Quintiliani, A. MANDiello, C. MARcocci, M. FAres, D. Cheloni, A. Frepoli, D. LATORRe, \\ A.M. LOMBARDi, M. MoretTi, M. PAstori, M. VAllocchia, A. Govoni, L. SCOGNAMiglio, A. BAsili, \\ A. MICHELINI AND S. MAZZA*
}

Istituto Nazionale di Geofisica e Vulcanologia

lucia.margheriti@ingv.it, mariagrazia.ciaccio@ingv.it,

\begin{abstract}
The central Italy seismic sequence, started with the $M_{w}=6.0$ Amatrice earthquake on August 24" 2016, is the first significant one after the Italian Seismic Bulletin (BSI) changed its analysis strategies in 2015.

These new strategies consist on the release of the BSI every four months, the review of the events with $M_{1} \geq$ 1.5 and the priority on the review of events with $M_{\mathrm{L}} \geq 3.5$. Furthermore, in the last year we improved the bulletin tools and made possible the analysis of all the stations whose data are stored in the European Integrated Data Archive (EIDA). The new procedures and software utilities allowed, during the first month of 2016 emergency, to integrate, in the Bulletin, the temporary stations installed by the emergency group SISMIKO, both in real-time transmission and in stand-alone recording.

In the early days of the sequence many of the BSI analysts were engaged in the monitoring room shifts, nevertheless at the end of August all events occurred in those days with $M_{L} \geq 4$ were analyzed; the largest event recovered and localized is a $M_{L}=4.5$ event immediately following the main shock.

In September 2016, 83 events with $M_{l} \geq 3.5$ were analyzed and re-checked, the number of pickings greatly improved. The focal mechanism of the main shock was evaluated using first motion polarities, and compared with the available Time Domain Moment Tensors and Regional Centroid Moment Tensor.

The first eight hours of the day on August 24", the most critical for the INGV surveillance room, were carefully analyzed: the number of located events increased from 133 to 408. The magnitude of completeness, after the analysis of the BSI, has dropped significantly from about 3.5 to 2.7. The mainshock focal mechanism and the relative locations of the first 8 hours' aftershocks give clues on the initial fault activation.

The seismic sequence in November 2016 is still ongoing; it included a mainshock of $M_{w}=6.5$ on October 30 "and 3 events of magnitude greater than 5.0 one on August 24" and two on October 26".
\end{abstract}

\section{INTRODUCTION}

$\mathrm{T}$ he $\mathrm{M}_{\mathrm{w}}=6.0$ earthquake occurred on August $24^{\text {t }} 2016$ at 01:36 UTC in central Italy near the Amatrice village triggering a seismic sequence which in the first month counts about 12000 events.

Locations and magnitudes of earthquakes recorded by the stations of the Italian $\mathrm{Na}$ tional Seismic

Network

\footnotetext{
* All the authors are at the Istituto Nazionale di Geofisica e Vulcanologia.
} 
(doi.org/10.13127/SD/XOFXNH7QFY), are evaluated in real-time in the surveillance room of the Istituto Nazionale di Geofisica e Vulcanologia (INGV) in Rome and made immediately available on the webpage of the Earthquakes National Center [Centro Nazionale Terremoti - CNT, (cnt.rm.ingvitit]. These events are then revised by the analysts of the Italian Seismic Bulletin (Bollettino Sismico Italiano - BSI), who double check the parameters, insert weights and polarity of seismic phases arrival times and finally integrate all the data available in the INGV acquisition system.

Starting in 2015 the BSI changes its strategies of revision: the events with $\mathrm{M}_{\llcorner} \geq 3.5$ are quickly reviewed while the standard review is done only for events with $\mathrm{M}_{\mathrm{t}} \geq 1.5$ [Nardi et al., 2015]. Moreover, the analysts can read signals from all the seismic stations available in the archive EIDA [European Integrated Data Archive,(eida.rm.ingv.it/), Mazza et al., 2012].

The Amatrice earthquake is the first major earthquake since we introduced these new BSI strategies of analysis; in the following we report the main actions undertaken and the results of the first month of the BSI group's work. These actions were partially codified in the emergency training test carried out by INGV in November 2015 [Pondrelli et al., 2016].

In the days immediately following the main shock, location and magnitude computation of the two most significant events occurred on August 24" were performed. Furthermore, we sought any significant shock in the early hours after the main shock, when it is quite common to fail in detecting significant events. Finally, we revised all events with $\mathrm{M}_{\mathrm{t}}$ $\geq 3.5$, from 24 August to 23 September 2016 and located all the events (between 00:00 and 08:00 UTC on August 24m) recorded by the automatic system operating at the surveillance room in Rome, but not analyzed in real-time. Preliminary analysis on the com- pleteness and on the hypocenters distributions of these "new" events are described hereinafter.

II. ITALIAN SEISMIC BULLETIN: STRATEGIES The BSI has been produced for decades by INGV. From 2015, BSI is publishing every 4 months and is available at cnt.rm.ingv.it/bsi; the contents of the 4 months are described in a technical document [Italian Seismic Bulletin 2015_1; 2015_2; 2015_3; 2016_1]. The current BSI format is QuakeML: it contains the locations with the error estimations, the magnitude $\left(M_{w}, M_{1}, M_{a}\right)$, the readings of $P$ and $S$ phases arrival times and the Time Domain Moment Tensor (TDMT).

The CNT developed some web services (webservices.rm.ingv.it/ws_fdsn.php) to facilitate the reading of QuakeML and to make the bulletin accessible to the national and international scientific community. In addition, the BSI data contribute information to the International Seismological Centre, which integrates INGV data within the European bulletin.

The BSI locations (1985-2016) are available in the database ISIDe [ISide Working Group, 2016] and in the web list of the CNT (cnt.rm.ingv.it/).

The magnitude threshold for which it is possible to locate an event in any part of the Italian territory (except for Sardinia and a few other exceptions) is approximately $\mathrm{M}_{\mathrm{L}}=1.7$ [Amato and Mele, 2008]. However, the realtime integration of data from various dense networks with data recorded by RSN (IV, doi .org / 10.13127 / SD / XOFXNH7QFY; MN, doi.org/10.13127/SD/FBBBTDTD6), provides, in some areas, the location of a very large number of smaller events. Since the end of 2014, the BSI Working Group decided to review only the events with $\mathrm{M}_{\mathrm{c}} \geq 1.5$, to maintain a certain homogeneity throughout the national territory and to make the work of the BSI analysts faster, hence allowing the quarterly releases.

Since January 2015, BSI analysts elaborate events with $M_{\iota} \geq 3.5$, i.e. "strong events", quickly in the days immediately following their occurrence, to provide better data in a short time. To analyze "strong events", dedi- 
cated tools have been developed, allowing the location of the events using only the nearest stations, but maintaining the association of all the arrival times to even the most distant stations (these readings are important for the studies on the deep structure of the Italian and European lithosphere and for more elaborate location analysis in 3D models). This new procedure gives greater completeness to the main product of the BSI, that is, the readings of the $\mathrm{P}$ and $\mathrm{S}$ arrival times, still allowing to get good localizations, despite the used crustal velocity model is extremely simple (see Tab. 1).

Table 1. Velocity model used by the INGV seismic surveillance and by the BSI analysts

\begin{tabular}{ccl}
\hline Thickness $(\mathrm{km})$ & $\mathrm{V}_{\mathrm{P}}(\mathrm{km} / \mathrm{s})$ & $\mathrm{V}_{\mathrm{s}}(\mathrm{km} / \mathrm{s})$ \\
\hline 11.1 & 5.00 & 2.89 \\
26.9 & 6.50 & 3.75 \\
half-space & 8.05 & 4.65 \\
\hline
\end{tabular}

In the last year it was also refined a tool that allows the analysts to manually read the amplitudes of the Wood-Anderson synthetic seismograms to improve the evaluation of $\mathrm{M}_{\text {. }}$. This improvement was necessary to minimize the mistakes made by the automatic system in the presence of multiple consecutive events, which is very common during a seismic sequence. Another paramount improvement was achieved at the beginning of 2016; since then BSI analysts can include in the bulletin all the stations stored in EIDA (eida.rm.ingv.it,www.orfeus-eu.org/data/eida/) and thus even temporary stations installed during the emergencies by SISMIKO [Moretti and SISMIKO Working Group, 2016; Moretti et al., 2014]. This new procedure ensures, during seismic emergency, the integration of the Italian National Seismic Network with a great number of stations installed near the epicenter and, therefore, a greater accuracy in the estimation of hypocenters (however the absolute value of the hypocenter depth is always function of the velocity model used).

\section{EVENTS WITH MAGNITUDE $\mathrm{M}_{\mathrm{c}} \geq 3.5$}

In the days following the $\mathrm{M}_{w}=6.0$ Amatrice earthquake on August 24 many of the BSI analysts were employed in the shifts of the
INGV surveillance room; nevertheless, they organized to quickly review the location of the main shock and of the second event with magnitude $\mathrm{M}_{\mathrm{L}}=5.4$. Moreover, they immediately started searching for significant shocks that eventually occurred in the hours after the main shock. By August 30" the main shock and all the events with $\mathrm{M}_{\mathrm{r}} \geq 4.0$ were analyzed. The new determination of the main shock hypocenter was published on August 31", after a formal communication to the Department of Civil Protection (DPC). In the same day an event with $\mathrm{M}_{\mathrm{r}}=4.5$, occurred at 01:37:26 UTC, less than a minute after the $\mathrm{M}_{w}=6.0$ event, but not localized in the monitoring room being hidden inside the seismogram of the previous shock, was recognized by the BSI analysts and published.

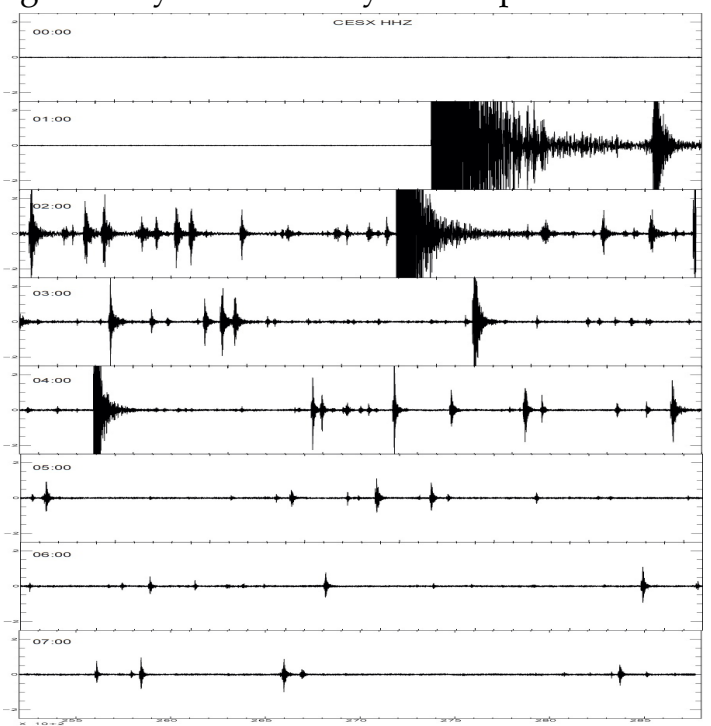

Figure 1 Continuous recordings (from 00:00 to 08:00 UTC of August 24t, 2016) of a RSN station located at some distance from the main shock epicenter: station CESX (Terni), about $50 \mathrm{~km}$ SW apart from the epicenter and about equidistant from Norcia and Amatrice.

The review of all aftershocks with $\mathrm{M}_{\mathrm{t}} \geq 3.5$ from August 24 to September 23, 2016, continued in September checking the list of earthquakes localized in the monitoring room. These were found to be more than 70 
(see Table A in supplementary electronic material), one with $\mathrm{M}_{\mathrm{L}} \geq 6.0$, one with a $5.0 \leq \mathrm{M}_{\mathrm{L}}<$ 6.0, and 14 events with $4.0 \leq \mathrm{M}_{\mathrm{L}}<5.0$. For all these events, BSI analysts reassessed the hypocenter's parameters and magnitude (Table A in supplementary electronic material); the latter, in some cases, was lower than the values estimated in the monitoring room. At the same time BSI analysts operated a visual inspection on the continuous recordings of some selected stations (i.e. Fig. 1); some events, initially processed in the surveillance room with magnitude below the $\mathrm{M}_{\mathrm{r}}=3.5$ threshold were re-analyzed. Events triggered in the automatic acquisition systems of Rome having $\mathrm{M}_{\llcorner}$above 3.5 were also checked. Moreover the BSI Working Group took advantage of the preliminary analysis done by the CNT monitoring group in the office of Ancona which performed automatic locations and magnitude estimations analyzing continuous data of INGV stations.

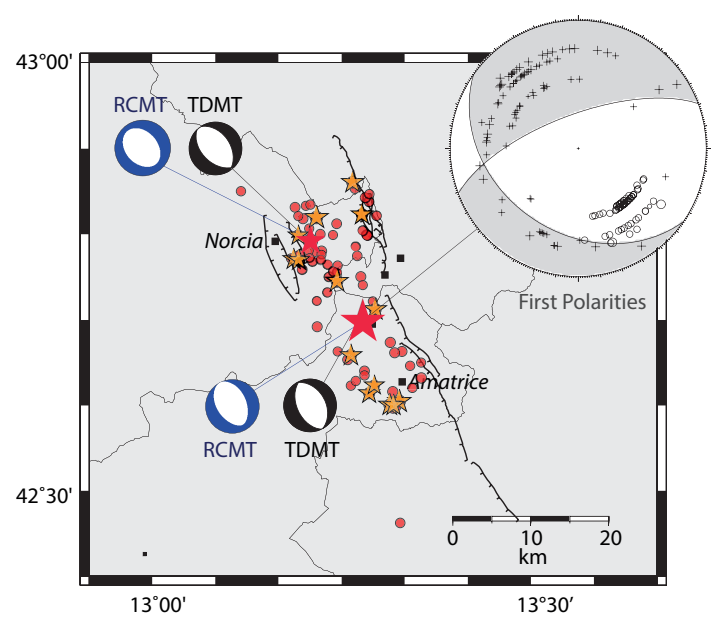

Figure 2: Map of the epicenters of the central Italy seismic sequence (24 august- 23 september 2016); the two red stars are the main shock and the largest, the orange star are events with $\mathrm{M}_{\mathrm{b}} \geq 4.0$, the red circles are events $3.5 \leq \mathrm{M}_{\mathrm{L}}<4.0$. The black lines show the main faults [EMERGEO working group 2016]. First polarities focal mechanism is shown together with TDMT and RCMT of mainshock and of larger aftershock..
The review of these "strong events" involved the analysis of the temporary seismic stations seismograms (18 stations T12 ** - Network IV [Moretti and SISMIKO Working Group, 2016] 1 station AM05 - Network XO [EMERSITO working group, 2016]).

In summary, 83 events with $\mathrm{M}_{\llcorner} \geq 3.5$ were revised (see Table A supplementary electronic material). Among these, 76 had been located in the monitoring room and 7 amended their $\mathrm{M}_{\llcorner}$in a value below 3.5 after the review, 3 events were retrieved and reviewed by the BSI analysts and then published in the first days after the main shock (including the $\mathrm{M}_{*}$ 4.5 occurred one minute after the main shock) and also other 4 events, with $\mathrm{M}_{\mathrm{L}} \geq 3.5$, were retrieved. The arrival times associated with hypocenter determinations of these 83 revised events increased by 8074 pickings for the $\mathrm{P}$ waves and by 463 pickings for the $\mathrm{S}$ waves; also, the amplitudes used to evaluate the magnitude increased by 1292 readings. The depths of the revised "strong events" range between about 6 and 12 kilometers, a very reduced variability if compared to the locations of the surveillance room, mainly thanks to the integration of temporary SISMIKO stations. The absolute values of the depth are, however, dependent on the velocity model used for location. The revised events (red and orange stars and red circles in Fig. 2) are located mainly to the North of the main shock, near Norcia, and, in general, are concentrated in the external fault sectors, the ones that experienced lower slip during the main shock [INGV Working Group, 2016]. Particular attention was paid to the analysis of the main shock focal mechanism using first polarity techniques. We improved the number of polarities of the first arrivals (150 polarities, 85 of them from stations in the distance range $<200 \mathrm{~km}$ ) and we were able to get a well-constrained focal mechanism [Hypoellipse code; Lahr, 1989; Reasenberg and Oppenheimer, 1985]. 
Table 2. Comparison between the first polarities focal mechanism, the TDMT and the RCMT for the mainshock

\begin{tabular}{|l|llll|lll|}
\hline Method & Lat. & Lon. & \multicolumn{2}{c|}{ Depth Mag. } & \multicolumn{3}{|c|}{ Strike Dip Rake } \\
& & & & & & \\
\hline FPFIT & 42.696 & 13.235 & 8.1 & Ml 6.0 & 130 & 40 & -40 \\
\hline RCMT & 42.71 & 13.22 & 10.0 & Mw 6.2 & 140 & 46 & -106 \\
& & & & & & & \\
\hline TDMT & 42.706 & 13.223 & 5.0 & Mw 5.96 & 155 & 49 & -87 \\
\hline
\end{tabular}

The resulting solution is very robust (quality factors $\mathrm{Qp}=\mathrm{A}, \mathrm{Qf}=\mathrm{A}$ ) and shows a significant strike slip component. Moreover, we compared it (Figure 2, Table 2) with the TDMT (cnt.rm.ingv.it/tdmt) and to the Quick RCMT (www.bo.ingv.it/RCMT/searchRCMT.html), both of them showing pure normal faulting(see Fig. 2 and Tab. 3). The different mechanism suggests that the rupture started as transtensive and then evolved in pure normal faulting.

\section{REVISION OF THE FIRST HOURS OF THE SEQUENCE}

In a seismic surveillance room, the hours immediately following a strong earthquake are the most critical, when the frequency of seismic events is greatest and support staff, provided in emergencies, is not yet operational [Pondrelli et al., 2016].

This circumstance leads to an inevitable incompleteness of the earthquake catalogue in the list of events located by the seismologists on shifts. For this reason, in September, we focused our analysis on the first eight hours of August 24 (from 00:00 to 08:00 UTC; Fig. 2). In particular, we revised all automatic locations performed by the Earthworm system [Pintore et al., this volume]. In these eight hours of the day the monitoring room located 133 events while the BSI located 408 events (light blue circles in Fig. 1). Then we performed a relative hypocenter location. The pickings of the BSI of the first eight hours of the day were analyzed using the HypoDD technique [Waldhauser and Ells- worth, 2000] to understand which portions of the faults have been activated by aftershocks in the early hours of the sequence (Fig. 3).

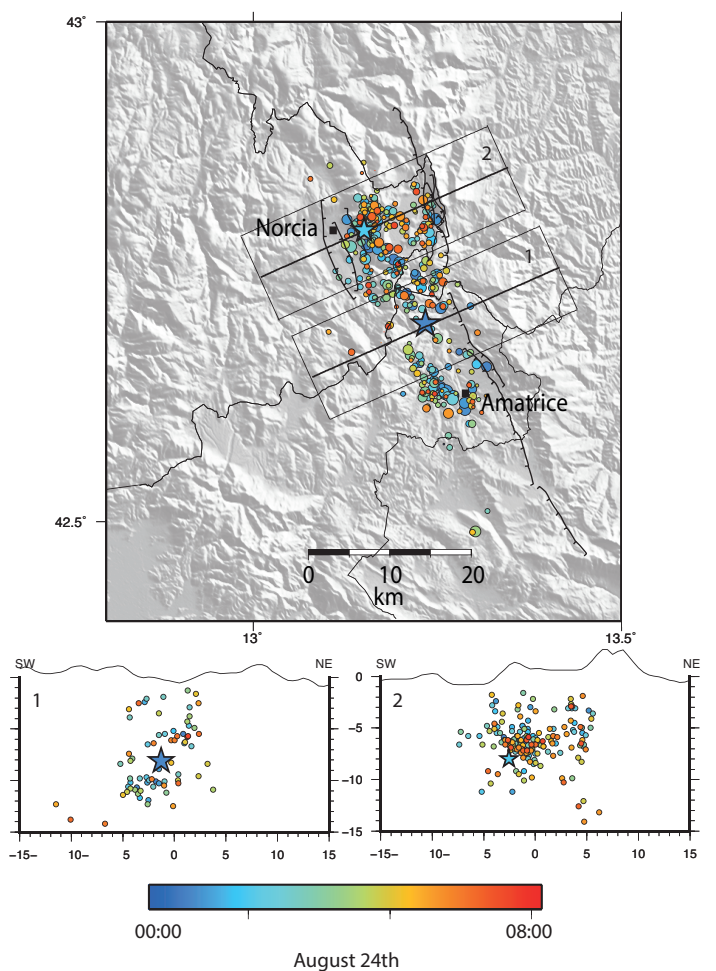

Figure 3: Map of the epicenters of the central Italy seismic sequence (earthquakes in the first 8 hours of August 24" 2016 00:00 - 08:00 UTC); the locations are made using relative location technique HypoDD; the two stars are the main shock and the largest aftershock of August 24"; other aftershocks are represented by circles, whose size is proportional to their magnitude while the color is a function of time. Cross sections show the hypocenters at depth (thickness of the sections $10 \mathrm{~km}$ ).

As illustrated in the map of figure 3 in the first 8 hours the seismicity already spread over quite a large volume about 30-km long and $15-\mathrm{km}$ wide, from Norcia to Amatrice. The fault system is quite simple toward S, while it gets more complicated toward $\mathrm{N}$ near Norcia. 
Finally, we estimate the completeness magnitude $(M c)$ and the b-value $(b)$ of the Gutenberg-Richter law for both the revised (Rev) and the not-revised (NRev) catalogues in the first 8 hours of the sequence. This is a tricky issue, given the complex magnitude distribution and the moderate number of events (Fig. 4). We estimate $M c$ by applying two different methods, all based on the maximum likelihood estimation of $b$-value. The Goodness of Fit method [GFT; Woessner and Wiemer, 2005] measures the probability $p r_{m}$ that the Gutenberg-Richter law explains the data above Mc. It identifies $M_{t}=2.7$ for the Rev catalogue as the best value of $M c$, giving $p r_{m}=94 \%$ (Fig. $4 \mathrm{a}$, green line with stars). The probabilities $\mathrm{pr}_{\mathrm{w}}$ are above $90 \%$ for Mc varying from $2.3(b=0.7)$ to about $3.1(b=1.0)$, but we judge that values smaller than $M_{\iota} 2.5$ are unlikely, giving the low related b-values, below 0.8 (Fig. 4a, blue line with stars). The value $M c=2.7$ is confirmed by the Completeness Magnitude and B-value Stability Method [MBS; Woessner and Wiemer, 2005], that measures the stability of the estimated b-values for Nbin consecutive magnitude bins. We apply the MBS method for Nbin varying from 5 to 15 , finding almost stable results (Fig. 4b). The correspondent values of $M c$ for the NRev catalogue are far larger. The GFT method gives values of $p r_{\text {s. }}$ lower than $90 \%$ and identifies as the best value $M c=3.0$ $\left(p r_{m}=86 \%\right)$. Anyway, the shape of the magnitude histogram (Fig. 4c) and the small bvalues (0.7-0.8) for $M c<3.4$ (Fig. 4a) suggest that the completeness magnitude might be close to $M c=3.5$.

In summary, we conclude that the most likely value of $M c$ is $2.7(b=0.9)$ for the Rev catalogue, but that some incompleteness might exists up to $M_{\llcorner}$3.1. The small size of the NRev catalogue does not allow us to reach conclusive results, but we judge that values of $M c$ below 3.5 are almost unlikely.
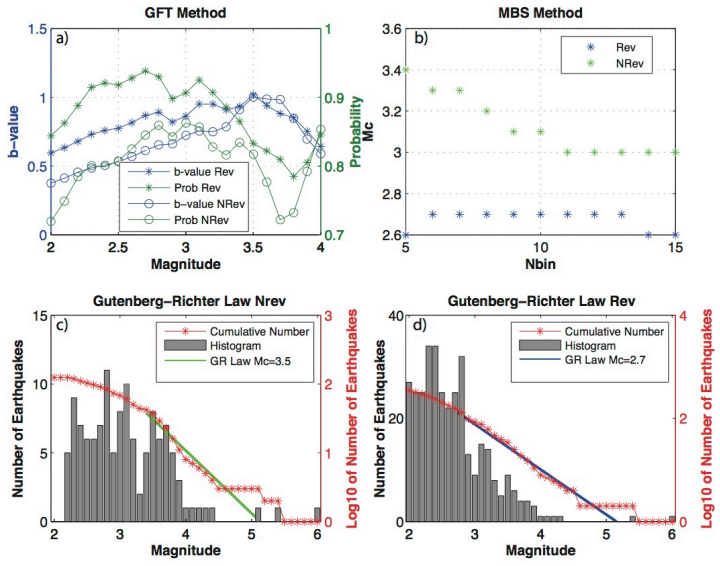

Figure 4: Estimation of the Completeness Magnitude Mc of the first 8 hours of August 24th. a) GFT method for both the Rev and the NRev catalogues: the blue and green lines mark the maximum likelihood b-values and the probabilities $p r_{M c}$ respectively, as function of Mc. b) MBS method for both the Rev and the NRev: the values of $M c$, as function of Nbin, are shown. c) distribution of magnitudes for the Nrev catalogue: the histogram of event magnitudes (for bin of 0.1) and the cumulative magnitude distribution (red stars) are shown; the green line marks the GutenbergRichter law for the most likely value of Mc. d) The same of panel c) but for the Rev catalogue.

\section{CONCLUSIVE REMARKS}

In this work we tried to give a comprehensive view of the steps that are necessary to validate data in order to include them in a seismic bulletin. We describe the work done by the analysts of the BSI during the first month of the central Italy seismic sequence which started on August 24 with an $\mathrm{M}_{w}=6.0$ near Amatrice town. According to the strategies defined by the BSI, we reviewed all the events with $\mathrm{M}_{2} \geq 3.5$ in the period 24/08 - $23 / 09$. Moreover we focused our analysis on the first eight hours of August 24 and estimated locations and magnitudes of this seismicity following the mainshock to get an idea of the fault system activated by the earthquake and made some statistical analysis to validate our work. 
The seismic sequence in November 2016 is still ongoing, it includes a mainshock of $\mathrm{M}_{w}=6.5$ on October 30th and 3 events of magnitude greater than 5.0 one on August 24th and two on October 26". The seismic monitoring room has located more than 30000 earthquakes; the work of the BSI analysts has just begun!

\section{Aknowledgments}

The BSI Working Group would like to thank all the INGV staff on shifts in the surveillance room in Rome for their work, the CNT personnel of the Ancona headquarters who made available a list of automatic locations and all operators who installed temporary stations for SISMIKO and EMERSITO. The study benefited from funding provided by the Italian Presidenza del Consiglio dei Ministri, Dipartimento della Protezione Civile (DPC); scientific papers funded by DPC do not represent its official opinion and policies.

\section{REFERENCES}

Amato, A. and F. M. Mele (2008). Performance of the INGV National Seismic Network from 1997 to 2007. Annals of Geophysics. doi: 10.4401 / ag-4454.

Bollettino Sismico Italiano 2016, doi:10.13127/BOLLETTINO / 2016.01 2015,doi:10.13127/BOLLETTINO/2015.01 2015, doi:10.13127 / BOLLETTINO/2015.0 2015,doi:10.13127/BOLLETTINO/2015.03

EMERGEO Working Group (2016). The 24 August 2016 Amatrice Earthquake: Coseismic Effects. Doi:10.5281/zenodo.61568

EMERSITO Working Group (2016). Rapporto preliminare sulle attività svolte dal gruppo EMERSITO a seguito del terremoto di Amatrice Mw 6.0 (24 agosto 2016, Italia centrale). Doi:10.5281/ zenodo.61884.

Gruppo di Lavoro INGV sul terremoto di Amatrice (2016). Secondo rapporto di sintesi sul Terremoto di Amatrice Ml 6.0 del 24 Agosto 2016 (Italia Centrale). Doi: 10.5281 / zenodo. 154400 .

Lahr J.C. (1989). HYPOELLIPSE/version 2.00: a computer program for determining local earthquakes hypocentral pa- rameters, magnitude and first motion pattern. U.S. Geol. Surv. Open-File Rep., 89116, 92 pp.

Mazza, S., A. Basili, A. Bono, V. Lauciani, A.G. Mandiello, C. Marcocci, F.M. Mele, S. Pintore, M. Quintiliani, L. Scognamiglio and G. Selvaggi (2012). EIDA - Seismic data acquisition, processing, storage and distribution at the National Earthquake Center, INGV. Annals of Geophysics, 55 (4); doi:10.4401/ag-6145.

Moretti M., Cattaneo C., Cecere G., Govoni A., Margheriti L. and S. Mazza (2014). Integrazione dei dati sismologici delle reti sismiche permanenti e temporanee. Regolamento e procedure. Rapporti Tecnici INGV, 276.

Moretti and SISMIKO Working Group (2016). Sismiko: emergency network deployment and data sharing for the 2016 Amatrice seismic sequence. This volume

Nardi A., et al. (2015). Bollettino Sismico Italiano: novità. $34^{\circ}$ GNGTS. Trieste, novembre 2015.

Reasenberg, P. and D. Oppenheimer (1985). FPFIT, FPPLOT and FPPAGE: FORTRAN computer programs for calculating and displying earthquake fault-plane solutions, U.S. Geol. Surv. O.File Rep. 85-739.

Pintore et al. (2016). INGV data lifecycle management system, performances during Mw 6.02016 Amatrice Earthquake Sequence. This volume.

Pondrelli S., et al. (2016). Pianificazione e gestione di un'emergenza sismica: esercitazione INGV del 26 novembre 2015 effettuata nell'ambito della Linea di Attività T5 "Sorveglianza sismica e operatività post terremoto". Quaderni di Geofisica.

Waldhauser, F. and W. L. Ellsworth (2000). A double-difference earthquake location algorithm: Method and application to the northern Hayward fault, California, BSSA, 90, 1353-1368, 2000.

Woessner, J., and S. Wiemer (2005). Assessing the quality of earthquake catalogues: Estimating the magnitude of completeness and its uncertainty Bulletin of the Seismological Society of America 95 (2), 684-698, 2005. 